\title{
Experimentações entre Dança e Saúde Mental ${ }^{\star}$

\author{
Mariana Tavares Cavalcanti Liberato $\star \star$ \\ Magda Dimenstein ${ }^{\star \star \star}$
}

\begin{abstract}
Resumo
Nosso objetivo foi discutir a utilização da dança no contexto da Reforma Psiquiátrica a partir da análise de um grupo de expressão corporal de um Centro de Atenção Psicossocial (CAPS). Para tanto, acompanhamos alguns de seus encontros, realizamos entrevistas com profissionais ligados ao mesmo e participamos de uma reunião da equipe. Vimos que esta experiência pode servir como um dispositivo da Reforma Psiquiátrica, possibilitando novas maneiras de lidar com a diferença, mas pode ser também capturada pela lógica manicomial. Além disso, o grupo serviu como um analisador da organização do serviço e da necessidade de criar formas distintas de cuidado.
\end{abstract}

Palavras-chave: dança; Reforma Psiquiátrica; produção de subjetividade.

\section{Experiments on Dance and Mental Health}

\begin{abstract}
We objective to discuss dance in the context of the Psychiatric Reform, through the analysis of a corporal expression group of the Center for Psychosocial Care (CAPS). We followed some meetings and we interviewed some professionals involved with it. We also participated in a group meeting. We observed that this experience can function as a Psychiatric Reform tool that enables new ways of dealing with the difference, but it can be perceived by the manicomial logic as well. Besides, the group was a means of reflection on the service structure and on the need to create new forms of care.
\end{abstract}

Keywords: dance; Psychiatric Reform; production of subjectivity.

\footnotetext{
^ Agência Financiadora: CNPQ.

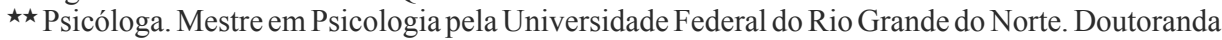
do Programa de Psicologia Social Integrado da Universidade Federal do Rio Grande do Norte. Endereço: Programa de Pós-Graduação em Psicologia Social - UFRN, CCHLA, Departamento de Psicologia. Campus Universitário, Lagoa Nova, Natal/RN. CEP: 59078-970. E-mail: mariana_liberato@yahoo.com.br

$\star \star \star$ Doutora em Saúde Mental pela Universidade Federal do Rio de Janeiro. Professora do Programa de Pós-Graduação em Psicologia Social da Universidade Federal do Rio Grande do Norte. E-mail:magda@ufrnet.br
} 


\section{INTRODUÇÃO}

As reflexões apresentadas neste artigo originaram-se da pesquisa de mestrado de uma das autoras que teve como objetivo investigar a experiência de um grupo de expressão corporal em dança em um Centro de Atenção Psicossocial (CAPS) II na cidade de Fortaleza, CE. Tal trabalho visou discutir a potência desinstitucionalizante deste dispositivo no processo de Reforma Psiquiátrica.

Para tanto, acompanhamos duas turmas quinzenais do grupo de expressão corporal, coordenadas pelo oficineiro, professor de dança e bailarino, durante quatro meses, registrando em áudio e em um diário de campo os momentos de conversa realizados no começo e no fim das atividades. Registramos também nossas conversas informais com o oficineiro, com o psiquiatra responsável pelo curso de formação dos artistas dos CAPS e com a coreógrafa que fez parte da formação artística do oficineiro no intuito de elucidarmos as concepções de corpo, dança e arte que norteavam tal trabalho. Entrevistamos, ainda, alguns técnicos mais próximos ao grupo e tivemos um momento de conversa com toda a equipe do CAPS, no qual pudemos discutir um pouco a inserção do grupo e dos artistas naquele contexto.

O trabalho corporal em dança proposto e desenvolvido pelo oficineiro encontra-se perfilado a certa perspectiva encontrada na dança contemporânea, que tem no corpo e no movimento seu fundamento. Esta não se resume a uma técnica ou a um repertório de movimentos, bem como não tem por objetivo a busca pela reprodução de passos idênticos ou pela representação (seja de histórias ou de sentimentos). O que há é uma tentativa de, mediante a experimentação do próprio movimento, criar no corpo circuitos de sensações que produzam dança e expressem esse processo.

Ressaltamos que essa é uma concepção possível de dança contemporânea compartilhada por alguns autores, coreógrafos, bailarinos e pesquisadores de dança, que percebemos ser também utilizada pelo oficineiro. Não objetivamos, absolutamente, encerrar tal movimento da dança em uma definição pronta e acabada, visto que a proposta da mesma baseia-se, exatamente, na possibilidade de pensar a dança de formas várias.

Nosso intuito, a partir dessa breve explanação, é discutir a invenção de uma dança menor, de um gaguejar no próprio corpo no contexto dessas oficinas. Deleuze e Guattari (1977) mostram-nos, ao tratar da obra de Kafka, que uma literatura menor é aquela que escapa, trazendo em seu bojo a dimensão do político e do coletivo e convocando outras potencialidades ao produzir novas formas de perceber e sentir. "Menor", conforme os próprios autores, não se refere a uma questão quantitativa, mas à produção de uma forma de expressão diferente daquela já sobrecodificada por uma língua maior, na qual tudo já possui uma significação a priori.

Tomamos de empréstimo esta noção de "menor" não no intuito de reproduzir um conceito, dando-lhe mais uma versão e retirando dele sua potência inventiva, mas, exatamente, por percebermos nele a positividade de produção de novos sentidos para um determinado campo. Ademais, inspirados no pensamento de Deleuze e Parnet (1998), podemos ratificar o pensamento que ora estamos 
expondo, complementando-o com a ideia de um gaguejar no próprio corpo. Os autores utilizam, em sua discussão, a expressão "gaguejar na própria língua" para explicar a invenção de um estilo que advém da necessidade de traçar uma linha de fuga, criando uma variação no sistema homogêneo do qual faz parte. Em última instância, gaguejar na própria língua significa a afirmação da potência de vida, da força, do devir de um agenciamento múltiplo.

A partir disso, podemos refletir: em que consiste produzir uma dança menor, um gaguejar no próprio corpo? Primeiramente, é necessário aprendermos que tal ideia não é relativa a uma individualidade. Ao contrário, o devir minoritário diz da criação de um povo porvir, de um agenciamento de heterogêneos que não busca uma síntese, uma significação sedimentada. É um movimento constante de forças e fluxos, que esburaca o plano molar e cria novos territórios existenciais, modos de expressão e sentidos. Inventar uma dança menor, portanto, refere-se também a uma forma diferente de fabricar corporeidades e relações consigo mesmo, com o tempo, com o espaço, com o movimento, com os outros, com a própria dança.

Tal ideia nos leva a pensar sobre o problema do valor estético dado a certo tipo de dança, o que nos faz perceber que este é um questionamento que se aplica à "dança maior", isto é, à dança entendida como um grande sistema ou uma grande escola ou, ainda, a um desejo de totalização de um movimento da dança (por exemplo, pensar "a dança contemporânea", como se dentro desse conjunto não houvesse diversos fluxos e multiplicidades virtuais). Todavia, se estamos trabalhando com a ideia de uma dança que escapa aos cânones sedimentados, pois tem como perspectiva a produção da diferença, as questões que devem ser engendradas são outras e são elas que desejamos discutir aqui.

\section{DanÇando entre a MeSMidade E A Diferença}

Um primeiro aspecto relevante acerca dessa dança menor produzida no âmbito do CAPS é a quem se destina e com qual finalidade. Vemos a necessidade desta reflexão, pois ainda é muito recorrente em nossa sociedade a ideia de que a prática da dança é restrita a poucos, tão somente para aqueles que têm uma capacidade nata, um dom divino ou anos de treinamento específico.

Se fôssemos pensar sob esta ótica, a proposição de um trabalho corporal num serviço substitutivo de saúde mental teria como objetivo apenas entreter ou ocupar os usuários participantes. Uma espécie de recreação, que embora muitas vezes seja exaltada por seu potencial lúdico e leve, cria a ideia de uma incapacidade dessas pessoas trabalharem com seus corpos na produção de novos sentidos.

Outra maneira de conceber esta atividade ainda sob a perspectiva de "uma dança para poucos" é aquela que toma a prática da dança como uma tecnologia disciplinar, isto é, um modo de fabricar corpos fortes, vigorosos e aptos a diferentes ações, mas que são esvaziados de sua potência de resistência e invenção. Corpos dóceis, domesticados, amansados, subordinados. Corpos que apreendem 
e cumprem as leis e as regras. Corpos modelados por padrões higienistas e de normalidade. Corpos aprisionados por correntes invisíveis, produzidas pelas repetições das "formas certas" e pelos discursos da média (FUGANTI, 2002).

Quando falamos dessa disciplinarização dos corpos não estamos tratando apenas da utilização de uma determinada técnica da dança, mas de toda uma pedagogia que produz essa forma "indivíduo". E também não estamos dizendo somente de uma forma específica de conduzir uma aula (com o uso de repetições que levem à perfeição do movimento, ao uso da cópia de passos etc.), mas de um modo de fabricar sujeitos e corpos que se adaptem a determinada realidade.

O que estamos expondo, portanto, é que há maneiras sutis e quase imperceptíveis de se promover essa disciplinarização, sendo elas percebidas em vários momentos, inclusive, como salvação. É o caso, por exemplo, de se ter como objetivo último de uma oficina como essa, a reabilitação social. Reabilitar quem? Para quê? E o que significaria reabilitar ou reinserir socialmente alguém através da dança? Seria fazer com que os usuários memorizassem uma coreografia para a apresentação em alguma festinha no próprio CAPS ou mesmo na comunidade? Seria fazer com que eles controlassem seus impulsos e "paixões" mediante a contagem dos oito tempos e da realização idêntica dos passos?

Encontramos ressonâncias de nossa preocupação em Benetton (1996) quando aponta que a reabilitação social remete-nos sempre a um estado de exceção, que cria dois grandes riscos para essa forma de lidar com a loucura, que é a de que vamos ter de mantê-la sempre em testes (para evitar uma nova "desabilitação") ou nunca poderemos considerar alguém reabilitado (pois isto significaria voltar a ser o que era antes e isso não é possível).

Vemos, assim, que a concepção de uma dança exclusiva para alguns finda por se conectar a formas de lidar com o espaço da oficina (no caso de nossa pesquisa, do grupo de expressão corporal) que se perfilam a modos instituídos de lidar com a loucura e com o corpo, articulados a uma lógica molar de exclusão e binarização da vida. A questão de inventar uma dança menor, então, volta a nos acossar e se torna urgente. Como produzir um espaço em que o gaguejar no próprio corpo seja possível e a reinvenção de si seja uma questão fundamental?

Paulo Caldas (2005) auxilia-nos ao propor uma aproximação entre uma determinada compreensão da filosofia de Espinosa e certa concepção de corpo na dança contemporânea. Ele explica que o pensamento espinosano ao declarar os modos de existência como afirmação de singularidade e de expansão da potência, afirma também o múltiplo. Isto significa, portanto, entender que cada corpo possui seus limites e que, no entanto, abarcam um infinito de possibilidades. É essa ideia que o autor indica insinuar, ao mesmo tempo, um princípio pedagógico (que ele denomina de "pedagogia da imanência" por se tratar de um reconhecimento das diferenças) e um manifesto coreográfico (que diz respeito à infinitude de qualquer corpo). 
É sobre esse último ponto que queremos nos deter, pois é através da ideia de que "um movimento qualquer de um corpo qualquer num espaço qualquer pode ser dança" (CALDAS, 2005, p. 3), que poderemos compreender a proposta do grupo de expressão corporal como um vetor potente de desinstitucionalização. O autor diz: "[...] nós reconhecemos na variedade infinita dos corpos uma possibilidade infinita de movimento e fomos capazes de colocar questões que nos trouxeram a consideração de um estatuto estético possível para diferentes inscrições do corpo qualquer" (CALDAS, 2005, p. 3).

É importante salientar que, para Caldas, há neste "movimento qualquer de um corpo qualquer" (CALDAS, 2005, p.3) uma dimensão poética que o lança no plano estético. É no sentido de composição dos elementos pelos quais se cria uma dança que podemos pensar em sua especificidade e seu estatuto ontológico, que vai além da representação de algo, visto que ela mesma já é algo no mundo.

Outra característica importante para pensarmos a dança em seu devir minoritário é que esta cria um corpo que abre passagem às intensidades estéticas. Como nos explica Moehlecke (2005), o corpo ao dançar é uma linguagem criadora de acontecimentos e o seu caráter intempestivo e intensivo possibilita a composição de singularidades e a abertura do corpo às forças do mundo, ao impessoal. A autora afirma ainda que a dança é a superação do próprio corpo, visto que este se desprende de uma identidade e experimenta novos contornos, acoplamentos, fluxos de energia, contágios.

A possibilidade de desfazer-se dessas figuras de identidade, criando novos diagramas subjetivos, aproxima essa perspectiva de dança ao paradigma de desinstitucionalização da loucura, pois busca desconstruir a ideia do louco como incapaz ou perigoso, libertando-o da exclusão e do estigma produzido pela psiquiatrização ao qual foi submetido. Podemos retomar a formulação basagliana de pôr a doença entre parênteses (BASAGLIA, 1985) e entendê-la como um convite a experimentar outras relações com a diferença, rompendo padrões e representações já fixadas e deixando-se afetar por esses encontros. Assim, a dança, conforme viemos discutindo, apareceria como mais um dispositivo possível nesse processo.

José Gil, em consonância com essa discussão sobre as misturas produzidas e a invenção de novas configurações de fluxos de subjetivação na experiência com a dança, expõe numa entrevista concedida a Denise Sant'Anna (1997) que a questão não está na imagem do corpo próprio dentro de seus limites como pensado por certa corrente da fenomenologia, mas no espaço criado pelo movimento do corpo, que prolonga suas fronteiras para além de seu próprio corpo.

Assim, torna-se clara a ideia de que o espaço, não só na dança, mas sempre que há um investimento afetivo no corpo, não é dado, mas construído, criado. $\mathrm{O}$ corpo torna-se um operador, um processo desencadeador de produção de imagens virtuais na dança que produz diferentes modos de perceber esse corpo. Criam-se vacúolos nesse espaço (que faz coexistir interior e exterior) por onde a energia dançante escoa e se propaga de um corpo a outro e é essa característica que faz o autor afirmar que a dança tem a vocação de formar grupos ou séries (GIL, 2004). 
A dança, nesta concepção, apresenta-se como potência de criação do espaço, do tempo (que é o tempo do acontecimento), de novas relações consigo mesmo e com os outros. Qualidades estas que nos remetem novamente à invenção de uma dança menor, uma dança singular, com sua potência e seus riscos. Um deles, como nos alerta Moehlecke (2005), o de cairmos no imperativo do devir, das experimentações sem prudência, esquecendo-nos que um pouco de território é necessário nesse processo de afecção, destruição e criação de modos de vida.

Isto posto, perguntamo-nos sobre o que vimos e experimentamos no grupo de expressão corporal em dança do CAPS. O que se passa ali, no entre? O que se produz naquele espaço?

\section{Movimentos ENTRE InSTituinte E INSTItuído}

Conforme dissemos alhures, nosso objeto de investigação foi o trabalho realizado pelo grupo de expressão corporal em dança de um CAPS II, na cidade de Fortaleza/CE. Baseando-nos na Filosofia da Diferença, utilizamos o conceito de dispositivo (DELEUZE, 1996) no intuito de pensar tal experiência como efeito do cruzamento de várias linhas que constituem nosso campo problemático. Deste modo, buscamos analisar as linhas de visibilidade e enunciação, de forças e de subjetivação, para produzir uma cartografia, ainda que mutável e parcial, deste encontro entre uma forma diferente de expressão pelo corpo e o campo da saúde mental.

Elegemos como os quatro grandes eixos da pesquisa os usuários do CAPS, participantes do grupo; o bailarino-oficineiro, coordenador do mesmo; a equipe do serviço e a própria pesquisadora, através da análise de sua implicação. ${ }^{1}$ Apesar de termos como foco o grupo de expressão corporal em dança e as relações que ali eram constituídas, percebemos no decorrer da pesquisa que tal experiência não se restringia a sua organização interna, mas indicava também questões relevantes para o CAPS e para a rede de serviços substitutivos, ainda em fase de estruturação.

Enfatizamos, ainda, que a discussão proposta procurou perceber, à luz da Análise Institucional, os movimentos complementares e de embate entre o instituído, ou seja, aquilo que já se encontra estabelecido, reconhecido e organizado; e o instituinte, que impele a mudanças, para compreender melhor o processo de institucionalização em curso.

Nesta seção, elencamos algumas reflexões construídas a partir de nosso encontro com o campo. Um primeiro ponto que pensamos ser importante discutir diz respeito à frequência com que os grupos aconteciam. Embora, à primeira vista, este pareça ser um aspecto meramente organizativo, percebemos que nos aponta questões muito mais amplas, como o próprio funcionamento do serviço, os modos de trabalho utilizados e a falta de estruturação efetiva de uma rede de assistência e suporte. 
A periodicidade quinzenal era uma problemática sempre discutida nos grupos, pois, tanto para o oficineiro, como para os participantes, seria mais interessante que o intervalo entre um encontro e outro fosse menor. Isto significava retomar os encontros semanais, como ocorriam no início da implementação de tal atividade no serviço, no início de 2006.

O oficineiro alegava dificuldade para dar continuidade ao trabalho, pois muitas vezes os participantes esqueciam o que tinha sido feito no encontro anterior ou mesmo a própria experiência corporal se perdia um pouco. Por sua vez, os participantes afirmavam que gostavam demais do grupo e que este fazia muito bem para eles.

Tal impasse existia, contudo, por conta da grande demanda para a atividade, o que fez com que a coordenação do CAPS modificasse os dias do grupo, de modo que houvesse mais grupos e mais pessoas pudessem ser atendidas. Surgiram-nos, então, alguns questionamentos: como é produzida toda essa demanda pelo grupo de expressão corporal em dança? Quais os efeitos, para os grupos em funcionamento, para o próprio oficineiro e para o serviço CAPS, dessa reorganização nos encontros? E o que essa grande procura pelo grupo e pelo serviço, como um todo, nos diz sobre a própria rede substitutiva e sobre o papel exercido pelo CAPS? ${ }^{2}$

Essas perguntas nos levam a duas inquietações: uma em relação aos usuários participantes, outra à própria inserção do artista-oficineiro no serviço. A respeito do primeiro aspecto, devemos refletir sobre o discurso de uma alta demanda para os grupos de expressão relacionando-o à frequência dos usuários nessa atividade, que não ocorria de forma constante (em um grupo com uma média de 20 participantes inscritos, a frequência era de, no máximo, um pouco mais da metade ).

Deste modo, para melhor organizar a procura, criou-se uma lista de integrantes para cada grupo, o que aponta para uma crescente procura pela atividade e que justifica a redução dos encontros de cada um deles (de semanais para quinzenais). No entanto, cotidianamente, observamos que talvez essa diminuição de números de encontros para ampliar a oferta da atividade não fosse tão necessária, caso se pensasse a questão além da necessidade de estruturação burocrática e técnica do serviço.

Não queremos, com isso, apontar erros na condução dessa sistematização ou nos colocarmos na posição de detentores da solução para tal problema. Também não é nossa intenção culpabilizar usuários ou técnicos, tampouco advogar uma restrição no acesso ao grupo. Ao contrário, o que pretendemos é problematizar a questão da quantidade de encontros e da presença dos usuários por outra lógica que não seja apenas a administrativa. Se pensarmos numa lógica de produção de desejo e de liberdade que nos parece mais pertinente a um trabalho como esse, veremos que talvez amarrar tão rigidamente os participantes em cada grupo pode não ser a melhor estratégia na gestão dessa atividade. 
Entendemos que há a necessidade de um mínimo de previsão no número de participantes, inclusive pelo tamanho reduzido do espaço onde ocorrem tais atividades, bem como é essencial manter tais grupos abertos e ao alcance de todos, possibilitando sempre a entrada de novos integrantes e o retorno dos antigos. Mas será que a forma adotada até então não tem servido mais em um sentindo oposto a esse? E com o agravante de poder comprometer a qualidade da proposta em detrimento da quantidade de pessoas inscritas na lista?

Tal reflexão nos leva ao segundo ponto, que concerne à inserção dos artistas-oficineiros (o que neste caso diz respeito não só ao oficineiro-bailarino, mas aos outros dois artistas - uma arte-terapeuta e um músico - que trabalham no serviço), que foram contratados em regime de prestação de serviço de 20 horas semanais, diferentemente da maioria dos outros técnicos da área da saúde, que foram contratados no mesmo período, mas em um regime de quarenta horas semanais. Além de um menor tempo para o trabalho, os artistas-oficineiros ainda têm de se dividir entre os dois CAPS dessa região (CAPS II - e o CAPSad - Álcool e outras Drogas), onde realizam suas atividades. Podemos entender, assim, não apenas a dificuldade em dar conta da alta demanda das oficinas, como também a sobrecarga de trabalho para esses profissionais, além da dificuldade destes participarem das reuniões de equipe, que facilitariam seu ingresso no serviço sob diferentes aspectos.

Não temos respostas fechadas ou prontas para dar a essas inquietações, mas percebemos que elas nos movem a pensar sobre a existência desse grupo no serviço, sua dinâmica, a articulação dele com as outras atividades e sobre a própria estruturação do CAPS. Lembramos também de Oliveira e Passos (2007), que advogam a inseparabilidade da clínica e dos processos de gestão de trabalho que estão sendo forjados, visto que a atitude terapêutica no CAPS deve ser pautada por novas formas de agenciar cuidado, acolhimento e estratégias de contrato. Dessa forma, processos de trabalho e gestão estão intimamente imbricados nesta outra perspectiva de assistência.

Quando nos questionamos sobre a alta demanda para os grupos de expressão, vemos que uma série de fatores está aí imbricada, mas nos chama a atenção pensar como ocorre a produção de desejo por essa oficina. Conversando com os técnicos, perguntamos sobre como eles faziam indicações para os grupos de expressão e alguns deles responderam que muitos usuários já vinham pedindo para participarem dessa atividade, que ouviram falar por algum conhecido, parente ou vizinho.

Constatamos que há essa produção de desejo nos diálogos que tínhamos com os participantes antes e depois do grupo propriamente dito. Muitos relatavam que queriam trazer parentes, pois eram muito bons aqueles momentos vivenciados ali, que faziam bem, passavam as dores e as tristezas. Outros diziam que aquilo que aprendiam ali ensinavam em casa, aplicavam nos amigos e em suas relações sociais. Ainda tinham aqueles que achavam tão importante que desejavam até que seus técnicos de referência participassem também, porque eles eram muito ocupados, estressados e cansados. 
Resgatando essas falas, volta-nos a indagação: mas o que, de fato, é tão bom? Que "mágica" (termo utilizado por uma das participantes) é essa que perpassa esses encontros? Seria possível expressar com palavras as sensações produzidas aí?

Concordamos com Moehlecke que há algo na dança que vai além do plano das representações, dos significados, das palavras. "São mistérios que passam pelo sensível, pelo corpo e trazem certa obscuridade, um non sense, enigmas do mundo" (MOEHLECKE, 2005, p.19). Encontramos também ressonâncias dessa ideia no pensamento de José Gil que declara que a dança conserva um elemento que escapa à semiotização (GIL, 2004). Tentemos, porém, dar algum sentido a essa experiência mediante nosso contato com o grupo.

A primeira consideração a que nos remetem as falas dos usuários é acerca de sua relação com seu próprio corpo. Embora para alguns as práticas do grupo de expressão ainda sejam entendidas apenas como exercícios físicos que contribuem para o ser saudável (discurso homogêneo na sociedade contemporânea), pois eles se sentem melhores após as atividades (relatando o cessamento de dores musculares e sintomas físicos), percebemos que para aqueles que frequentam o grupo há mais tempo e com mais assiduidade existe uma diferença entre a proposta daquele trabalho para o de um trabalho essencialmente de exercícios físicos, como por exemplo, o proposto pela educadora física do serviço. Alguns, inclusive, conseguem perceber o grupo de expressão corporal como uma forma de dança. Nas palavras de uma usuária: "essa verdadeira dança que mistura corpo e alma".

O caráter flexível da proposta do grupo, assim como a sintonia, o cuidado e o respeito com o outro foram aspectos marcantes desse trabalho, que nos parece ratificar a ideia da produção de uma dança menor e de outra forma de vivenciar o corpo e as relações. O oficineiro comentou-nos que, para ele, estar em sala dando aula é bastante diferente de estar na posição de bailarino/intérprete, pois o papel de professor, em sua compreensão, exige uma maior responsabilidade com as pessoas que ali estão. Percebemos isto, por exemplo, no zelo que ele tinha com os participantes em deixá-los à vontade para que fizessem as atividades respeitando seus limites, o que nos remete à proposta de Caldas de uma "pedagogia da imanência" bem distinta do princípio pedagógico da disciplina e da virtuose.

No período em que acompanhamos os grupos, foram propostas atividades diversas, como, por exemplo, formas distintas de andar na sala (explorando espaços, trocando objetos, de costas, de lado, de braços dados, com obstáculos etc.), exercícios de mudança de peso, contato-improvisação, manipulação do corpo do outro, automassagem, alongamento, entre outros. Alguns foram utilizados em vários encontros, o que nos levou a questionar o oficineiro sobre como lidava com essa repetição não só dos exercícios e da escolha das músicas, mas também nas formas de falar e perguntar.

Ele respondeu-nos que está atento e toma cuidado para que isso não fique engessado, cristalizado, mas que é um caminho que ele acredita que funciona e que é a partir deste caminho, construído por ele através da sua experiência como aluno e professor, que vê possibilidades de "pegar vários atalhos". 
Podemos, portanto, indagar se o que se produz é uma repetição do mesmo, uma reprodução do que já é conhecido, uma recognição pelo conforto de já se saber antecipadamente aonde se quer chegar ou se, nessa repetição, há a invenção de algo novo, algo que escapa à sobrecodificação e cria estranhamento, desterritorializações que exigem outras formas de expressão.

De acordo com Cerqueira (2006), neste momento em que as oficinas terapêuticas já se fixaram como dispositivos instituídos em serviços substitutivos como os CAPS, a criação é, muitas vezes, preterida em lugar da execução. A repetição seria, assim, entendida como cristalização de modelos e práticas, levando a um aprisionamento das forças de reinvenção e nos jogando em direção aos modelos interiorizados de forma de cuidado e de relação.

Por outro lado, podemos compreender, com o auxílio do pensamento de Deleuze (2000), que a repetição efetua a diferença. Para este autor, a repetição não está ligada à ideia de reprodução do mesmo, do semelhante, como também não é da ordem da generalização ou da generalidade, mas da produção do singular, pois aquilo que se repete é sempre a diferença.

A ideia de repetição enunciada por Deleuze aponta para a dimensão do virtual, do devir, daquilo que escapa à codificação, à fixidez, à homogeneidade. Diz do próprio movimento de invenção, de experimentação de novas formas. Podemos pensar, pois, em que situações a repetição no grupo de expressão corporal trabalha em função de produzir diferença e quando ela age em favor da manutenção da mesmidade, muitas vezes, apenas disfarçada numa nova roupagem.

É Cerqueira (2006) quem ainda nos ajuda nesta questão ao propor que o uso da arte no CAPS como meio expressivo necessita avançar ao encontro dos ideais da luta antimanicomial, criando, de fato, "máquinas estéticas" que mais do que expressar a subjetividade privativa de cada um, possibilite a criação de novos estilos. Para tanto, diz a autora, seria necessário um profissional disponível à experimentação e que fosse além da rigidez das regras, dos especialismos e da técnica.

Percebemos que nosso oficineiro se aproxima desta posição ao estabelecer relações dentro do grupo que passam pela potência de criação, através do contato e do contágio, da abertura às singularidades e à invenção de outras possibilidades tanto na sua própria vida, como na dos usuários e na vida do próprio serviço. Observamos, ainda, que muito dessa potencialidade está intrinsecamente ligada e possibilitada pela experimentação desse corpo.

Lembramos novamente de Caldas (2005) ao se referir à repetição como um mecanismo de impressão de circuitos de sensação no corpo. São essas marcas que tornarão possíveis a fruição da dança e a liberdade para improvisar e compor, como também a produção de, como já dito, um pensamento pelo movimento e a criação de um estilo singular.

Pensemos na criação de um estilo também em relação ao oficineiro, em sua maneira de interligar seus pressupostos teóricos e técnicos, sua formação como bailarino e sua experiência no serviço, compondo outras formas de dançar sua própria vida. Ele teve uma formação inicial em academias particulares de balé 
clássico, integrando depois uma companhia independente, que possuía uma proposta de experimentação das possibilidades trazidas por técnicas diversas, construindo uma compreensão e uma prática de dança bastante singular, mas que se aproxima à concepção de dança contemporânea da qual estamos tratando.

Em sua inserção no campo da saúde mental, o oficineiro-bailarino participou do curso ministrado por um psiquiatra responsável pela formação e acompanhamento dos artistas nos CAPS, o que lhe provocou novas inquietações, curiosidades e trouxe outros elementos para o seu trabalho, como a perspectiva fenomenológica, base teórica da Educação Somática, já utilizada por ele em suas aulas.

É interessante percebermos como ele vai passeando por diversos olhares e técnicas, pois, segundo o que nos relatou, aquilo que ele experimentou em seu corpo fica marcado e funciona como ferramentas no seu trabalho. Aos nossos olhos acadêmicos, tais articulações podem muitas vezes parecer estranhas ou ainda, sem rigor, mas logo lembramos que uma teoria é uma caixa de ferramentas, que se multiplica e cria outras teorias (FOUCAULT, 2003).

Além de experimentar no próprio corpo várias técnicas e buscar conhecer e estudar diversos autores da área da dança e das teorias corporais alternativas, a dança para o oficineiro foi se desenhando, principalmente, como uma forma de relação. Encontramos ressonâncias dessa compreensão acerca do modo de trabalhar com a dança na perspectiva do "contato-improvisação", prática muito utilizada por ele.

O "contato-improvisação" (CI) foi criado pelo bailarino e coreógrafo Steve Paxton e se baseia "no toque e no equilíbrio entre duas pessoas. Os parceiros em dueto tocam muito um ao outro e, por meio do toque, a informação sobre o movimento de cada um é transmitida" (FREIRE, 2001, p. 50). Esta, no entanto, é apenas uma definição formal para este modo de dança que não indica a amplitude de seus efeitos sobre quem a pratica.

Segundo José Gil (2004), o CI é um diálogo, uma comunicação entre os corpos, em que a energia flui, propiciando a continuidade do movimento. Por meio dele, se estabelece uma conexão complexa, que implica em diferentes dimensões (sensorial, mental e reflexo) e propicia a experiência de sentir o inconsciente dos movimentos do outro (o que Gil chama de small dance).

O CI possibilita uma experiência de reciprocidade, na qual "a consciência do contato que um bailarino tem contém não a experiência do outro, mas a consciência que este último tem dessa experiência (e que é a consciência de que o primeiro bailarino tem a mesma experiência que ele)" (GIL, 2004, p.112).

Essas interferências entre as consciências dos bailarinos, que são "consciências do corpo", abrem-se à osmose entre essas duas consciências, impregnando-se uma a outra e esburacando-as mutuamente. É esse processo que José Gil denomina abertura à comunicação de inconscientes, que se refere, exatamente, aos movimentos e velocidades virtuais produzidos nos corpos que são imperceptíveis ao pensamento. 
Se fizermos uma aproximação entre este pensamento e a ideia de encontro em Espinoza, já discutida alhures, perceberemos que o CI produz encontros que possibilitam o aumento de potência, ganho de intensidade, pois como nos diz Gil (2004, p.112), "graças a uma comunicação inconsciente de experiências, cada corpo acolhe a experiência do outro". Esse contágio produzido pela dança não significa uma perda de singularidade, mas a criação de uma "atmosfera" em que as forças que afetam os corpos se intensificam e se afetam. Além de que há corpos que se harmonizam melhor que outros neste processo.

O CI pode ser tomado, então, não apenas como uma ferramenta técnica, mas principalmente como um exercício ético-estético, que não obstante seja detonador de processos de contágio e aumento de potência, requer cuidado e prudência para que a libertação dessas intensidades produzidas no encontro entre os corpos não se precipitem em sujeições e dominações (GIL, 2004).

Esta experiência com a dança e com o contato com o outro nos possibilita um modo de vivenciar e refletir acerca da intensidade dos encontros e dos efeitos decorrentes deles. Quando nos deparamos com a diferença e nos dispomos a compor com ela, o que não significa uma espécie de identificação ou homogeneização, novas compreensões e afecções se tornam possíveis e nos põem em movimento, em devir.

Apesar de enxergarmos a potência dessa atividade notamos que, frequentemente, o instituído intervém e faz deste espaço mais um meio de normatização e estabilização do que de extravasamento. Percebemos, em alguns momentos, certa "pedagogia do controle" a partir da docilização do corpo e das sensações e que não é produzida somente pelo oficineiro, mas pelos outros técnicos e até pelos próprios usuários. Lembramo-nos, então, de Dimenstein (2004), quando nos adverte que devemos atentar para o risco de mantermos uma "subjetividade manicomial", caracterizada pela internalização de dispositivos de segregação, mascarada por uma pseudodesinstitucionalização.

O que nos parece importante reiterar é que o grupo de expressão corporal, assim como outras estratégias e ferramentas, pode tanto ser potência de transformação de práticas e saberes como também pode servir como armadilha e captura dos modos de vida. É a coexistência do instituinte e do instituído, em uma luta de força que nos mobiliza a buscar sempre novas armas que possibilitem ao grupo ser espaço de experimentação e invenção. 


\title{
Notas
}

\begin{abstract}
${ }^{1}$ A análise da implicação é um conceito-ferramenta proposto pela Análise Institucional, que não diz respeito a um julgamento valorativo ou maniqueísta de um compromisso, mas refere-se ao trabalho de pensar acerca da posição assumida e das escolhas conscientes e inconscientes, a partir de um nó de relações de forças e formas institucionais que nos perpassam, abandonando à ilusão da neutralidade (ALTOÉ, 2004).

${ }^{2}$ Não obstante esta última indagação não seja o foco de nossa discussão neste momento, achamos fundamental explicitá-la, pois nos faz refletir acerca dos limites da rede assistencial estrita, bem como nos faz pensar sobre o processo de constituição recente dessa rede na cidade e suas conseqüências. Acreditamos que discussões como essas são imprescindíveis na construção de novas possibilidades de ação e reflexão no processo da Reforma Psiquiátrica não somente de Fortaleza, como do Brasil.
\end{abstract}

\section{REFERÊNCIAS BibLIOGRÁFICAS}

ALTOÉ, S. (Org.). René Lourau: Analista Institucional em Tempo Integral. São Paulo: HUCITEC, 2004.

BASAGLIA, F. (Coord.). A instituição negada: relato de um hospital psiquiátrico. Rio de Janeiro: Graal, 1985.

BENETTON, M. J. Terapia Ocupacional e Reabilitação Psicossocial: uma relação possível? In: PITTA, A. (Org.). Reabilitação Psicossocial no Brasil. São Paulo: Hucitec, 1996. p. 143-149.

CALDAS, P. O corpo qualquer. In: ENCONTRO INTERNACIONAL DE DANÇA E FILOSOFIA, 1., 2005, Rio de Janeiro. Trabalho não publicado.

CERQUEIRA, A. C. Nem tudo o que reluz é ouro: oficinas terapêuticas no cenário da Reforma Psiquiátrica. 2006. Dissertação (Mestrado)Universidade Federal do Rio Grande do Norte, Natal, 2006.

DELEUZE, G. O Mistério de Ariana. Lisboa: Veja, 1996.

. Diferença e Repetição. Lisboa: Relógio d'Água, 2000.

DELEUZE, G.; GUATTARI, F. Kafka: por uma literatura menor. Rio de Janeiro: Imago, 1977.

DELEUZE, G.; PARNET, C. Diálogos. São Paulo: Escuta, 1998. 
DIMENSTEIN, M. A reorientação da atenção em Saúde Mental: sobre a qualidade e humanização da assistência. Psicologia Ciência e Profissão, Brasília, v. 24, n. 4, p. 112-117, 2004.

FOUCAULT, M. Microfisica do poder. Rio de Janeiro: Graal, 2003.

FREIRE, I. M. Dança-educação: o corpo e o movimento no espaço do conhecimento. Cadernos Cedes, Campinas, ano XXI, n. 53, abr. 2001.

FUGANTI, L. Projetos Solos do Brasil. Disponível em: http:// denisestoklos.uol.com.br/solosdobrasil/aula_fuganti.doc. Acesso em: 08 set. 2007. Transcrição da aula aberta sobre filosofia em 02 de setembro de 2002.

GIL, J. Movimento total. São Paulo: Iluminuras, 2004.

MOEHLECKE, V. O dançar do corpo: experimentações rebeldes no contemporâneo. 2005. Dissertação (Mestrado)-Universidade Federal do Rio Grande do Sul, Porto Alegre, 2005.

OLIVEIRA, J. A. M.; PASSOS, E. H. A implicação de serviços de saúde mental no processo de desinstitucionalização da loucura em Sergipe: um problema clínico-político. Vivência, UFRN/CCHLA, Natal, n. 32, p. 259-274, jan./jun., 2007.

SANT'ANNA, D. B. Entrevista com José Gil. Cadernos de Subjetividade. Núcleo de Estudos e Pesquisas da Subjetividade do Programa de Estudos Pós-Graduados em Psicologia Clínica da PUC-SP, São Paulo, v. 5, n. 2, p. 253-266, 1997.

Recebido em: abril de 2008

Aceito em: março de 2009 